\title{
Development and Characterization of Buccal Bilayer Tablets containing Microparticles with Ibuprofen
}

\author{
J. Conceição*, M. Estanqueiro, M. H. Amaral, P. Lobão, P. Costa, J. M. Sousa Lobo \\ Research Centre for Pharmaceutical Sciences, Laboratory of Pharmaceutical Technology, Department of Drug Sciences, Faculty of \\ Pharmacy, University of Porto, Porto, Portugal \\ *Corresponding author: jmgmconceicao@ff.up.pt
}

Received October 17, 2014; Revised November 01, 2014; Accepted November 04, 2014

\begin{abstract}
The aim of this study was to develop and characterize buccal bilayer tablets containing ibuprofen microparticles, prepared through emulsion/chilling method, to obtain a sustained release. In this way, three formulations of bilayer tablets containing three bioadhesive polymers, namely Noveon ${ }^{\circledR}$ AA-1 Polycarbophil USP, Carbopol $^{\circledR} 974$ and Carbopol ${ }^{\circledR} 980$ were prepared. Weight uniformity, friability, hardness and in vitro drug release studies, by two different methods, were evaluated in the manufactured tablets. The calculation of similarity factor $\left(f_{2}\right)$ was also carried out. In addition, three gels $(0.5 \%, \mathrm{w} / \mathrm{w})$ with the same polymers were prepared and textural analysis (firmness and adhesiveness) were assessed in comparison with the bioadhesive layer of tablets. Buccal bilayer tablets with suitable physical properties (weight uniformity, hardness and friability) were produced. In vitro dissolution tests, performed during 8 hours, have demonstrated a sustained release of ibuprofen (maximum drug released: 30.0 - 45.1\%). According to $f_{2}$, both dissolution methods and the three studied polymers showed similar dissolution profiles $\left(f_{2}>50\right)$. Tablets containing Carbopol ${ }^{\circledR} 974$ showed higher values of firmness and adhesiveness after $6 \mathrm{~h}$ of hydration in phosphate buffer $\mathrm{pH}$ 7.4. On the other hand, it was not possible to verify a relationship between the textural parameters of the gels and the bioadhesive layer of tablets containing the same polymers.
\end{abstract}

Keywords: Buccal Bilayer Tablets, Bioadhesive Polymers, Microparticles, Ibuprofen, Sustained Release

Cite This Article: J. Conceição, M. Estanqueiro, M. H. Amaral, P. Lobão, P. Costa, and J. M. Sousa Lobo, "Development and Characterization of Buccal Bilayer Tablets containing Microparticles with Ibuprofen." American Journal of Medical Sciences and Medicine, vol. 2, no. 5 (2014): 109-114. doi: 10.12691/ajmsm-2-5-5.

\section{Introduction}

Bilayer compacting technology has gained more popularity in recent times, because bilayer tablets offer several advantages over conventional tablets [1]. For instance, such tablets are commonly used to avoid chemical incompatibilities of formulation components by physical separation, and release profiles may be modified by combining layers with various release patterns, or by combining slow-release with immediate-release layers [2].

Buccal drug delivery offers many advantages in comparison to oral delivery, such as, the avoidance of first-pass hepatic metabolism, leading to higher bioavailability and the drug withdrawal possibility [3,4].

Buccal delivery of the desired drug using mucoadhesive polymers has been the subject of interest since the early 1980s [5]. Several formulations have been developed earlier using mucoadhesive polymers like ointments [6], patches [7], films [8,9], tablets [10,11] and gels [12,13] containing different classes of drugs including antimicrobials (for example, metronidazole and miconazole nitrate), corticosteroids (for example, hydrocortisone acetate and triamcinolone acetonide), antiepileptics (for example, carbamazepine), local anesthetics (for example, lidocaine), etc. [4,5].
Bioadhesive polymers should possess certain physicochemical features including hydrophilicity, numerous hydrogen bond-forming groups, flexibility for interpenetration with mucus and epithelial tissue, and visco-elastic properties [14]. Hydrogels are hydrophilic matrices that absorb water when placed in an aqueous media, and are composed of polymers such as polyacrylates (Carbopol and Polycarbophil), ethylene vinyl alcohol, polyethylene oxide, poly vinyl alcohol, poly (N-acryloylpyrrolidine), polyoxyethylenes, self-cross linked gelatin, sodium alginate, natural gums like guar gum, karaya gum, xanthan gum, locust bean gum and cellulose ethers like methyl cellulose, hydroxypropyl cellulose, hydroxypropyl methylcellulose, sodium carboxy methyl cellulose, etc. [15].

Nano and microparticle carriers have important potential applications for the administration of therapeutic molecules [16]. Microparticles can have numerous advantages, as a good biocompatibility, low toxicity, high stability, and can improve efficacy, absorption, and bioavailability [16,17]. Some of the methods for production of lipid microparticles include: doubleemulsion solvent evaporation, emulsion/chilling, fluid supercritical, atomization and extrusion [17-25].

Ibuprofen (Figure 1) is an analgesic and antiinflammatory drug (NSAID) used in the treatment of inflammatory diseases and for pain relief of oral mucositis, 
and was used as a model drug of class II of Biopharmaceutical Classification System (BCS), characterized by high permeability but poor solubility [26]. Maximum ibuprofen plasma concentrations are achieved 1 to 2 hours after oral administration, but because of this drug's short biological half-life (2 hours), the therapeutic plasma concentration can be maintained only if ibuprofen is administered frequently $[27,28]$. These characteristics make ibuprofen a suitable candidate for buccal administration by a sustained release mucoadhesive tablet.

The major objectives of this study were: (i) to prepare and to characterize lipid microparticles with ibuprofen; (ii) to develop and to characterize buccal bilayer tablets containing ibuprofen microparticles to obtain a sustained release with three hydrophilic polymers with high mucoadhesive properties, such as Noveon ${ }^{\circledR}$ AA-1 Polycarbophil USP, Carbopol $^{\circledR} 974$ and Carbopol ${ }^{\circledR}$ 980; (iii) to investigate the in vitro drug release; (iv) to evaluate firmness and adhesiveness of the bioadhesive layer of tablets and to compare these textural parameters with gels $(0.5 \%, \mathrm{w} / \mathrm{w})$ prepared with the same bioadhesive polymers.

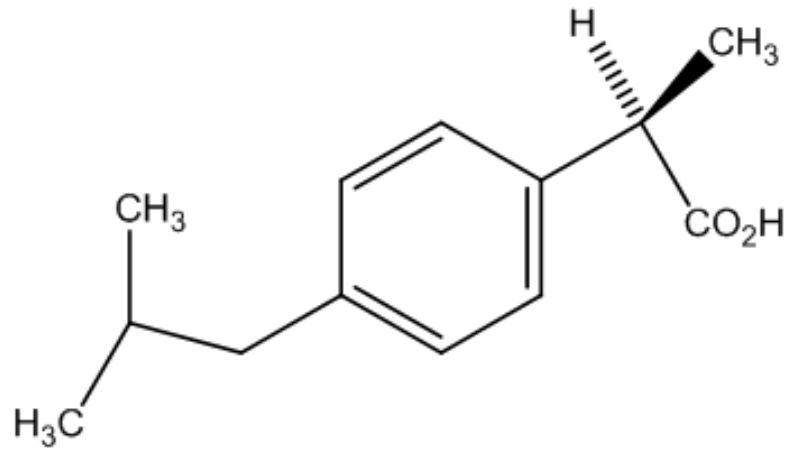

Figure 1. Chemical structure of ibuprofen

\section{Materials and Methods}

\subsection{Materials}

Ibuprofen (Roig Farma, Spain), hydrogenated castor oil (Cutina ${ }^{\circledR}$ HR) (José M. Vaz Pereira SA, Portugal), monosodium phosphate (José M. Vaz Pereira SA, Portugal), disodium phosphate anhydrous (José M. Vaz Pereira SA, Portugal), propylene glycol (José M. Vaz Pereira SA, Portugal), Tween ${ }^{\circledR} 80$ (Sigma-Aldrich, United States of America), chloroform (José M. Vaz Pereira SA, Portugal), Noveon ${ }^{\circledR}$ AA-1 Polycarbophil USP (Lubrizol, Brussels), $\quad$ Carbopol $^{\circledR} 980$ NF Polymer (Lubrizol, Brussels), and Carbopol ${ }^{\circledR} 974$ NF Polymer (Lubrizol, Brussels) were used.

\subsection{Preparation of Lipid Microparticles}

Lipid microparticles of 1:2 ibuprofen/hydrogenated castor oil (Cutina ${ }^{\circledR}$ HR) ratio were prepared using the emulsion/chilling method [17]. The lipophilic excipient was melted on a hot plate $\left(85-88^{\circ} \mathrm{C}\right)$ under stirring at 600 rpm and ibuprofen was added [17]. The oil phase was slowly added to a Tween ${ }^{\circledR} 80$ solution $(1.5 \%$, w/w) at the same temperature, followed by the quick addition of a mixture of water:propylene glycol $(75: 25)$ at $0^{\circ} \mathrm{C}$, maintaining the agitation at $600 \mathrm{rpm}$ [17]. The obtained lipid microparticles were filtered and washed with water [17].

\subsection{Determination of Drug Encapsulation Efficiency (EE\%)}

For the determination of ibuprofen content in lipid microparticles, $75 \mathrm{mg}$ of sample was dissolved in chloroform (50 mL) and analyzed using a UV-VIS spectrophotometer (Jasco, model V-650, Japan) at $272 \mathrm{~nm}$. Drug calibration curve was previously prepared (y = $\left.0.989 x+0.029 ; R^{2}=0.999\right)$. EE\% was calculated using the following equation:

$$
E E \%=\frac{W_{m}}{W_{i}} \times 100
$$

where $W_{m}$ is the amount of ibuprofen in lipid microparticles and $W_{i}$ is the amount of ibuprofen used.

\subsection{Particle Size Analysis and Morphological Characteristics}

Particle size measurements were determined using a laser diffraction particle size analyzer (Mastersizer 3000, Malvern Instruments, United Kingdom) with a range from 0.01 to $3500 \mu \mathrm{m}$. The determination was performed at room temperature using 1.6 for the refractive index, 0.1 for the absorption index, laser obscuration around $6 \%$ and scattering model mie. The dispersant was water with Tween ${ }^{\circledR} 80$, and each sample was tested five times at 2000 rpm. The results were, respectively, expressed using volume distributions by the volume weighted mean (D $[4,3]$ ), surface weighted mean (D [3,2]), 10\% percentile (Dv [10]), median (Dv [50]) and 90\% percentile (Dv [90])

The particle morphologies were also observed and captured by the inverted microscope (Motic ${ }^{\circledR}$, model AE2000, China).

\subsection{Manufacture of Tablets}

Three types of bilayer tablets containing three bioadhesive polymers, namely Noveon $^{\circledR}$ AA-1 Polycarbophil USP, Carbopol ${ }^{\circledR} 974$ and Carbopol ${ }^{\circledR} 980$ were prepared using a single-punch compression machine (Korsh 9048-71, Maschinenfabrik, Germany) with 13 mm diameter punches as follows: the first layer with a weight of $300 \mathrm{mg}$, responsible for the tablet retention on the mucosa, was obtained by compression of each one of the bioadhesive polymers; the second layer with a weight of $338 \mathrm{mg}$, responsible for buccal drug delivery, containing the lipid microparticles corresponding to $100 \mathrm{mg}$ of ibuprofen, was then added to the first layer and tablets were obtained by compaction of the two layers.

\subsection{Weight Uniformity, Friability and Hardness of Tablets}

To study tablet weight uniformity, 20 tablets of each formulation were weighed using an analytical balance (Mettler Toledo, Mettler AE 200, Switzerland). For each formulation the hardness of 10 tablets was also evaluated using a tablet hardness tester (Erweka GmbH, Erweka TBH 28, Germany). 
Friability was determined by submitting 10 previously weighed tablets to falling shocks for $4 \mathrm{~min}$ in a friabilator (Electrolab, EF-1W, India), set at $25 \mathrm{rpm} / \mathrm{min}$. After $4 \mathrm{~min}$, the tablets were reweighed and the percentage of friability was calculated.

\subsection{In Vitro Release Studies}

The in vitro drug release study was performed using a dissolution apparatus (Sotax, model AT7, Switzerland) according to the paddle method at $50 \mathrm{rpm}$. The dissolution medium consisted of $1000 \mathrm{~mL}$ of phosphate buffer $\mathrm{pH} 7.4$ [29] at $37.0 \pm 0.5^{\circ} \mathrm{C}$. The collection times were $30,60,120$, 180, 240, 360, 480 minutes, and the volume of sample collected was $10.0 \mathrm{~mL}$ (without volume replacement and with the same adjustment in calculations).

The dissolution tests were performed by two different methods: A and B. In the method B the tablets were attached at a height of $7.0 \mathrm{~cm}$ to the inside of the dissolution vessel [30], and in method A, the tablets were positioned on the bottom of the dissolution vessel [31].

The samples, collected at established times, were filtered and the drug concentration was determined by a UV-VIS spectrophotometer (Jasco, model V-650, Japan). Drug calibration curve was previously prepared $\left(\lambda_{\max }=\right.$ $\left.272.0 \mathrm{~nm} ; \mathrm{y}=1.459 \mathrm{x}+0.004 ; \mathrm{R}^{2}=0.996\right)$. Dissolution studies were made in triplicate and results were registered as the average \pm standard deviation (SD).

The dissolution profiles of tablets were compared using the $f_{2}$ similarity factor as follows [32,33]:

$$
f_{2}=50 \times \log \left\{\left[1 / \sqrt{1+\frac{1}{n} \sum_{j=1}^{n}\left(R_{j}-T_{j}\right)^{2}}\right] \times 100\right\}
$$

where $n$ is the number of time points, $R_{j}$ is the mean percent reference drug dissolved at time $j$ after initiation of the study, and $T_{j}$ is the mean percent test drug dissolved at time $j$ after initiation of the study.

\subsection{Evaluation of Firmness and Adhesiveness of the Bioadhesive Layer of Tablets and Gels}

Firmness and adhesiveness were assessed at $20^{\circ} \mathrm{C}$ in the bioadhesive layer of tablets after $6 \mathrm{~h}$ and $16 \mathrm{~h}$ of hydration in phosphate buffer $\mathrm{pH} 7.4$ [29]. In addition, three gels $(0.5 \%$, w/w) were prepared with the same bioadhesive polymers and the same textural parameters were also evaluated.

Firmness and adhesiveness measurements were performed using a texture analyzer (Stable Micro Systems, TA-XT2i, United Kingdom) by carrying out a penetration test using a load cell of $5 \mathrm{Kg}$, a cylindrical probe $(6 \mathrm{~mm}$ diameter for tablets and $25 \mathrm{~mm}$ in the case of gels), a penetration depth of $2 \mathrm{~mm}$ and velocities of $3 \mathrm{~mm} / \mathrm{s}$ and a trigger force of $0.049 \mathrm{~N}$. After penetrating the sample, the probe returned to a position $90 \mathrm{~mm}$ above the platform surface. The maximum force (firmness) and the negative area (adhesiveness) were obtained from the graphic force (N) versus distance $(\mathrm{mm})$ [34]. All the measurements were performed in triplicate and data were statistically analyzed by one-way ANOVA followed by Tukey post hoc test $\left(\right.$ IBM $^{\circledR}$ SPSS $^{\circledR}$ Statistics, version 22). A value of $\mathrm{p}<0.05$ was considered significant.

\section{Results}

Lipid microparticles with ibuprofen, a BCS class II drug, through emulsion/chilling method were prepared (Figure 2). The result of the drug encapsulation efficiency was $87.4 \%$.

The median size of lipid microparticles (Dv [50]) was $75.90 \pm 0.55 \mu \mathrm{m}$. The particle size range can be represented as mean (Dv [10]) and mean (Dv [90]) which were, respectively, $6.30 \pm 0.08 \mu \mathrm{m}$ and $167.00 \pm 1.26 \mu \mathrm{m}$. The volume weighted mean (D [4,3] and the surface weighted mean (D [3,2]) were, respectively, $83.3 \mu \mathrm{m}$ and $14.8 \mu \mathrm{m}$.

The buccal bilayer tablets presented suitable physical properties (Figure 3) and Table 1 shows the obtained results for weight uniformity, hardness and friability.
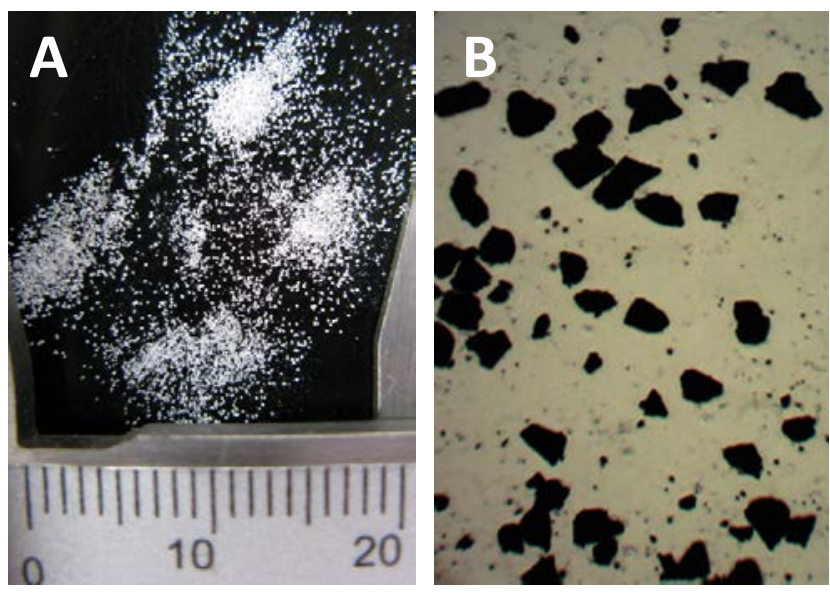

Figure 2. Lipid microparticles with ibuprofen (A - macroscopic aspect, scale in millimeters; B - microscopic aspect, magnification of 40x)
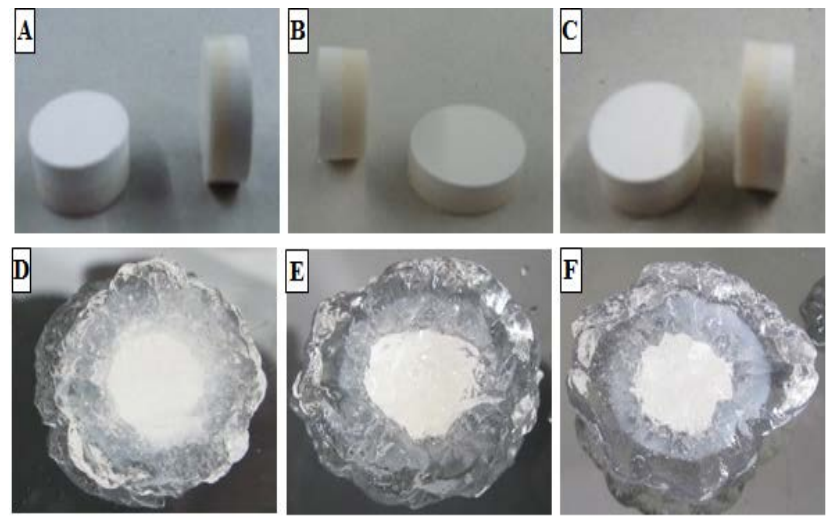

Figure 3. Appearance of the buccal bilayer tablets before and after $16 \mathrm{~h}$ of hydration in phosphate buffer $\mathrm{pH}$ 7.4. (A - tablets with Carbopol ${ }^{\circledR} 974$; B - tablets with Polycarbophil; C - tablets with Carbopol ${ }^{\circledR} 980$; D - tablets with Carbopol $^{\circledR} 974$ after $16 \mathrm{~h}$ of hydration; E - tablets with Polycarbophil after 16 h of hydration; F - tablets with Carbopol ${ }^{\circledR} 980$ after $16 \mathrm{~h}$ of hydration)

Table 1. Results of weight uniformity (mean \pm SD, $n=20$ ), hardness (mean $\pm S D, n=10)$ and friability (mean $\pm S D, n=10)$ of the buccal bilayer tablets

\begin{tabular}{|c|c|c|c|}
\hline Tablets & Weight (mg) & Hardness (N) & Friability (\%) \\
\hline Polycarbophil & $652 \pm 11$ & $161 \pm 34$ & 0.88 \\
\hline Carbopol $^{\circledR} 974$ & $635 \pm 6$ & $123 \pm 15$ & 0.55 \\
\hline Carbopol $^{\circledR} 980$ & $622 \pm 21$ & $76 \pm 25$ & 0.91 \\
\hline
\end{tabular}


Figure 4 shows the dissolution profiles of buccal bilayer tablets by two different methods: A and B. The results of firmness and adhesiveness of the bioadhesive layer of tablets, after $6 \mathrm{~h}$ and $16 \mathrm{~h}$ of hydration in phosphate buffer $\mathrm{pH}$ 7.4, and gels are illustrated in Figures 5 and 6, respectively.

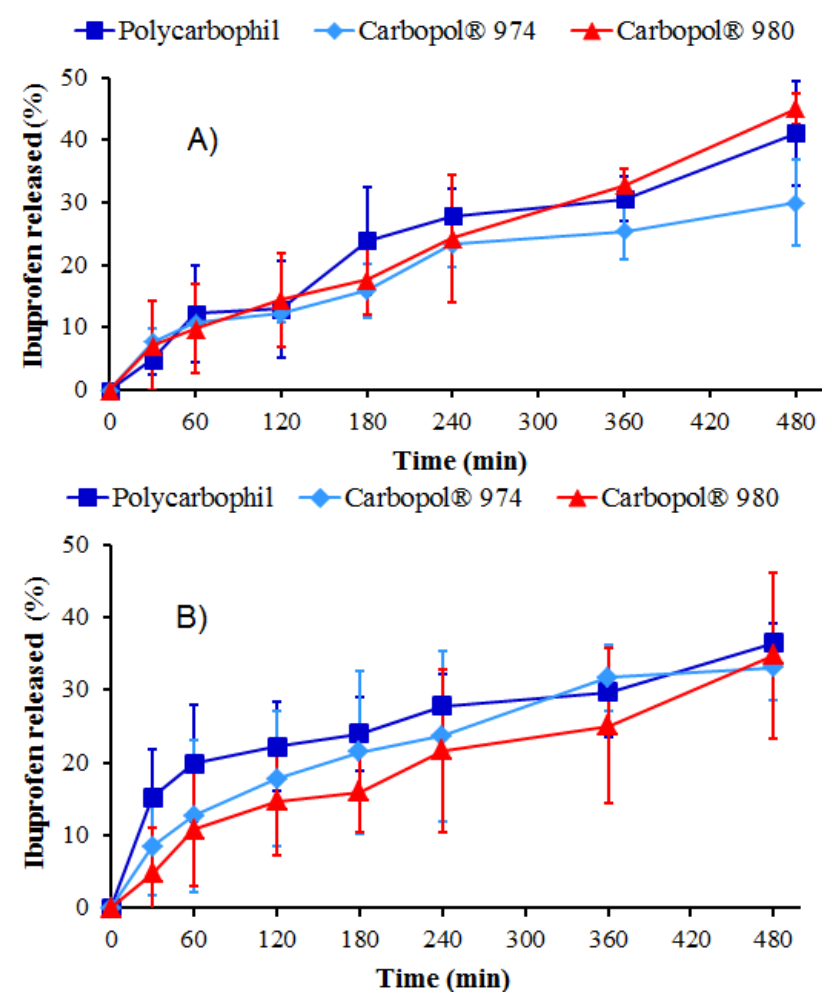

Figure 4. In vitro release profiles of buccal bilayer tablets $(n=3$, mean \pm $\mathrm{SD}$ ). (A - dissolution performed positioning the tablet on vessel bottom (method A); B - dissolution performed positioning the tablet on internal vessel surface at $7 \mathrm{~cm}$ from the bottom (method B)
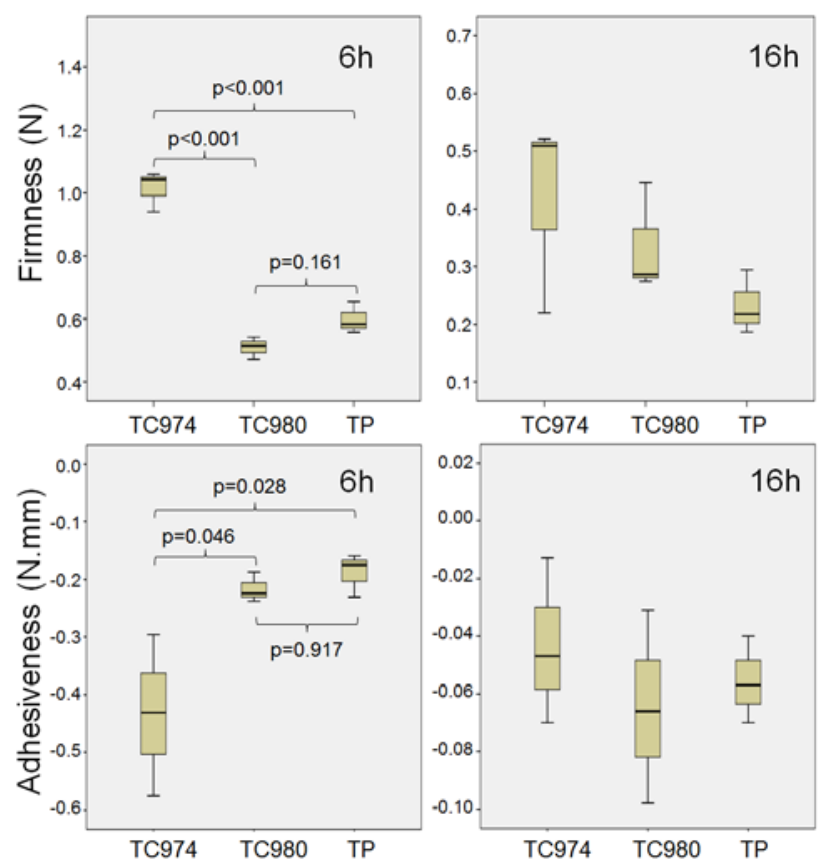

Figure 5. Box plot of firmness and adhesiveness of bioadhesive layer of tablets after $6 \mathrm{~h}$ and $16 \mathrm{~h}$ of hydration in phosphate buffer $\mathrm{pH}$ 7.4. (TC974 - tablets with Carbopol ${ }^{\circledR}$ 974; TC980 - tablets with Carbopol ${ }^{\circledR}$ 980; TP - tablets with Polycarbophil)
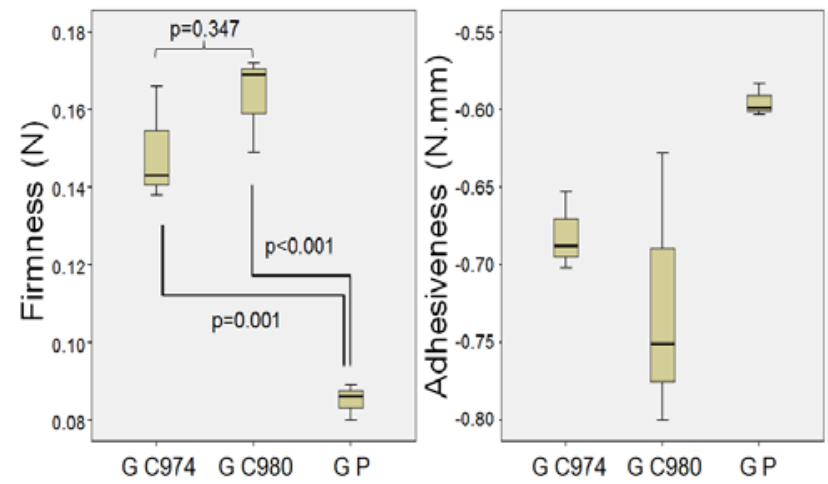

Figure 6. Box plot of firmness and adhesiveness of gels. (G C974 - gel with Carbopol ${ }^{\circledR}$ 974; G C980 - gel with Carbopol ${ }^{\circledR}$ 980; G P - gel with Polycarbophil)

\section{Discussion}

Three types of bilayer tablets containing ibuprofen microparticles to obtain a sustained release with three bioadhesive polymers, Noveon ${ }^{\circledR}$ AA-1 Polycarbophil USP, Carbopol $^{\circledR} 974$ and Carbopol ${ }^{\circledR} 980$, with uniform aspect and weight, friability $<1 \%$, and suitable hardness were prepared.

The sizes of the lipid microparticles were all within the micrometer range, indicating that the emulsion/chilling method was able to achieve the intended objective. The EE\% of ibuprofen in lipid microparticles was high (87.4\%).

Many researches were devoted to the development and characterization of microparticles for the delivery of ibuprofen [17,35-40]. For instance, Zhang et al. [36] concluded that trehalose and glucose are effective cryoprotectants and mannitol and sucrose are not very good cryoprotectants for the ibuprofen-loaded solid lipid microparticles as they crystallize during the freeze-drying process.

During the development of a medicinal product a dissolution test is used as a tool to identify formulation factors that are influencing and may have a crucial effect on the bioavailability of the drug [32]. In vitro dissolution tests (Figure 4), performed during 8 hours, have demonstrated a sustained release of ibuprofen (maximum drug released: 30.0 - 45.1\%). Two different methods were followed in dissolution tests considering two possible tablet positions in the vessel [30,31]. An $f_{2}$ value between 50 and 100 suggests that the two dissolution profiles are similar [32]. According to the results of $f_{2}$, both dissolution methods (A and $\mathrm{B}$ ) showed similar dissolution profiles $\left(f_{2}>50\right)$ and the same results were obtained with the tablets containing the three types of polymers studied.

Several methods to study mucoadhesion of polymers and dosage forms were published in the last 30 years [41]. Nevertheless, a comparison of the results is hardly feasible, because of different experimental set-ups [41].

It can be observed in Figure 5 that tablets with Carbopol $^{\circledR} 974$ exhibit higher firmness (related to the maximum force) and adhesiveness (related to the negative area) than tablets with Carbopol ${ }^{\circledR} 980$ and Noveon ${ }^{\circledR}$ AA-1 Polycarbophil USP, after 6 hours of hydration in phosphate buffer $\mathrm{pH} 7.4$ [34]. On the other hand, the 
adhesiveness and firmness of Carbopol ${ }^{\circledR} 980$ and Noveon $^{\circledR}$ AA-1 Polycarbophil USP were quite similar.

A pronounced decrease of textural parameters was observed for all polymers after 16 hours of hydration. This fact may be due to dispersion of the polymer in the buffer solution and consequent erosion of the matrix resulting in the reduction of firmness and adhesiveness. The gel with Noveon ${ }^{\circledR}$ AA-1 Polycarbophil USP (Figure 6) showed values of firmness and adhesiveness significantly lower than those of the other polymers tested.

\section{Conclusions}

In this work, three formulations of buccal bilayer tablets containing ibuprofen microparticles with suitable physical properties (weight uniformity, hardness and friability) were prepared. In vitro dissolution tests have demonstrated a sustained release of ibuprofen. According to $f_{2}$, both dissolution methods ( $\mathrm{A}$ and $\mathrm{B}$ ) and the three polymers studied showed similar dissolution profiles.

As expected, a decrease in the adhesiveness and firmness of bioadhesive layers was observed with the increase of hydration time of tablets in phosphate buffer pH 7.4 (6 h versus 16 h). Tablets containing Carbopol ${ }^{\circledR}$ 974 showed higher values of firmness and adhesiveness after $6 \mathrm{~h}$ of hydration. This means that this polymer showed the best bioadhesive properties and is more suitable to be used in the formulation of buccal tablets. However, it was not possible to verify a relationship between the textural parameters of the gels and the bioadhesive layer of tablets containing the same polymers. For tablets with Carbopol ${ }^{\circledR} 980$, firmness after $6 \mathrm{~h}$ of hydration was lower than tablets with Carbopol ${ }^{\circledR} 974$, in opposition to what happened in the gels case in which firmness from both polymers was similar. The lower firmness in tablets with Carbopol $^{\circledR} 980$ after 6 h of hydration seemed to be related with the lower capacity of this polymer to compact originating more friable tablets with lower hardness.

\section{Statement of Competing Interests}

The authors have no competing interests.

\section{References}

[1] Kottala, N., et al., "Influence of compaction properties and interfacial topography on the performance of bilayer tablets”, Int $J$ Pharm, 436 (1-2). 171-8. 2012.

[2] Abebe, A., et al., "Review of bilayer tablet technology", Int $J$ Pharm, 461 (1-2). 549-58. 2014.

[3] Kanjanabat, S., Pongjanyakul, T., "Preparation and characterization of nicotine-magnesium aluminum silicate complex-loaded sodium alginate matrix tablets for buccal delivery”, AAPS Pharm Sci Tech, 12 (2). 683-92. 2011.

[4] Sudhakar, Y., Kuotsu, K., Bandyopadhyay, A.K., "Buccal bioadhesive drug delivery-a promising option for orally less efficient drugs”, J Control Release, 114 (1). 15-40. 2006.

[5] Salamat-Miller, N., Chittchang, M., Johnston, T.P., "The use of mucoadhesive polymers in buccal drug delivery", Adv Drug Deliv Rev, 57 (11). 1666-91. 2005.

[6] Bremecker, K.D., Strempel, H., Klein, G., "Novel concept for a mucosal adhesive ointment”, J Pharm Sci, 73 (4). 548-52. 1984.
[7] Nair, M.K., Chien, Y.W., "Development of anticandidal delivery systems: (II) mucoadhesive devices for prolonged drug delivery in the oral cavity”, Drug Dev Ind Pharm, 22 (3). 243-53. 1996.

[8] Kohda, Y., et al., "Controlled release of lidocaine hydrochloride from buccal mucosa-adhesive films with solid dispersion”, Int $J$ Pharm, 158 (2). 147-55. 1997.

[9] Rossi, S., et al., "Buccal delivery of acyclovir from films based on chitosan and polyacrylic acid", Pharm Dev Technol, 8 (2). 199208. 2003.

[10] Ali, J., Khar, R.K., Ahuja, A., "Formulation and characterization of a buccoadhesive erodible tablet for the treatment oforal lesions", Pharmazie, 53 (5). 329-34. 1998.

[11] Perioli, L., Pagano, C., "Preformulation studies of mucoadhesive tablets for carbamazepine sublingual administration”, Colloids Surf B Biointerfaces, 102. 915-22. 2013.

[12] Shin, S.C., Bum, J.P., Choi, J.S., "Enhanced bioavailability by buccal administration of triamcinolone acetonide from the bioadhesive gels in rabbits”, Int J Pharm, 209 (1-2). 37-43. 2000.

[13] Jones, D.S., et al., "Physicochemical characterization and preliminary in vivo efficacy of bioadhesive, semisolid formulations containing flurbiprofen for the treatment of gingivitis”, J Pharm Sci, 88 (6). 592-8. 1999.

[14] Batchelor, H., Novel bioadhesive formulations in drug delivery, The Drug Delivery Companies Report Autumn/Winter, Pharma Ventures Ltd., 2004.

[15] Mishra, P.R., et al., "Hydrogels as drug delivery system”, Indian Drugs, 33 (5). 181-6. 1996.

[16] Ravi Kumar, M.N., "Nano and microparticles as controlled drug delivery devices”, J Pharm Pharm Sci, 3 (2). 234-58. 2000.

[17] Almeida, H., Amaral, M.H., Lobão, P., "Comparative study of sustained-release lipid microparticles and solid dispersions containing ibuprofen”, Braz J Pharm Sci, 48 (3). 529-36. 2012.

[18] Mahajan, H.S., Gattani, S.G., "Gellan gum based microparticles of metoclopromide hydrochloride for intranasal delivery: development and evaluation”, Chem Pharm Bull, 57 (4). 388-92. 2009.

[19] Freitas, S., Merkle, H.P., Gander, B., "Microencapsulation by solvent extraction/evaporation: reviewing the state of the art of microsphere preparation process technology", J Control Release, 102 (2). 313-32. 2005.

[20] Kang, Y., et al., "Preparation of PLLA/PLGA microparticles using solution enhanced dispersion by supercritical fluids (SEDS)", $J$ Colloid Interface Sci, 322 (1). 87-94. 2008.

[21] Gouin, S., "Microencapsulation: industrial appraisal of existing technologies and trends", Trends Food Sci Technol, 15 (7-8). 33047. 2004.

[22] Vezzù, K., et al., "Production of lipid microparticles containing bioactive molecules functionalized with PEG”, $J$ Supercrit Fluids, 54 (3). 328-334. 2010.

[23] Chambi, H.N.M., et al., "Solid lipid microparticles containing water-soluble compounds of different molecular mass: Production, characterisation and release profiles”, Food Res Int, 41 (3). 229236. 2008.

[24] Müller, R.H., Mäder, K., Gohla, S., "Solid lipid nanoparticles (SLN) for controlled drug delivery-a review of the state of the art", Eur J Pharm Biopharm, 50 (1). 161-77. 2000.

[25] Soppimath, K.S., Kulkarni, A.R., Aminabhavi, T.M., "Encapsulation of antihypertensive drugs in cellulose-based matrix microspheres: characterization and release kinetics of microspheres and tableted microspheres”, J Microencapsul, 18 (3). 397-409. 2001.

[26] Sogias, I.A., Williams, A.C., Khutoryanskiy, V., "Chitosan-based mucoadhesive tablets for oral delivery of ibuprofen”, Int J Pharm, 436 (1-2). 602-10. 2012.

[27] Lopes, C.M., et al., "Compressed matrix core tablet as a quick/slow dual-component delivery system containing ibuprofen", AAPS Pharm Sci Tech, 8 (3). E76. 2007.

[28] De Brabander, C., et al., "Bioavailability of ibuprofen from matrix mini-tablets based on a mixture of starch and microcrystalline wax”, Int J Pharm, 208 (1-2). 81-6. 2000.

[29] European Pharmacopoeia, $8^{\text {th }}$ ed., EDQM, Council of Europe, Strasbourg, 2014.

[30] Miyazaki, S., et al., "Oral mucosal bioadhesive tablets of pectin and HPMC: in vitro and in vivo evaluation", Int J Pharm, 204 (12), 127-32. 2000.

[31] Remuñán-López, C., et al., "Design and evaluation of chitosan/ethylcellulose mucoadhesive bilayered devices for buccal drug delivery”, J Control Release, 55 (2-3). 143-52. 1998. 
[32] Guideline on the investigation of bioequivalence, Committee for medicinal products for human use (CHMP), European Medicines Agency (EMA), London, 2010.

[33] Moore, J.W., Flanner, H.H., "Mathematical comparison of dissolution profiles", Pharm Tech, 20 (6). 64-74. 1996.

[34] Bourne, M.C., “Texture profile analysis”, Food Technol, 32. 62-72. 1978.

[35] Ofokansi, K.C., et al., "Formulation and evaluation of glutaraldehyde-crosslinked chitosan microparticles for the delivery of ibuprofen”, Trop J Pharm Res, 12 (1). 19-25. 2013.

[36] Zhang, L., et al., "The effects of cryoprotectants on the freezedrying of ibuprofen-loaded solid lipid microparticles (SLM)", Eur J Pharm Biopharm, 69 (2). 750-9. 2008.

[37] Perge, L., et al., "New solid lipid microparticles for controlled ibuprofen release: formulation and characterization study", Int $J$ Pharm, 422 (1-2). 59-67. 2012.
[38] Wikarsa, S., et al., "The improvement of ibuprofen dissolution rate through microparticles spray drying processed in an aqueous system”, Drug Dev Ind Pharm, 34 (5). 485-91. 2008.

[39] Conceição, J., et al., "Development and characterization of mucoadhesive bilayer tablets", in $9^{\text {th }}$ World Meeting on Pharmaceutics, Biopharmaceutics and Pharmaceutical Technology, Lisbon, Portugal. 2014.

[40] Conceição, J., et al., "Development and characterization of buccal bilayer tablets containing microparticles of ibuprofen", in $X^{\text {th }}$ Spanish-Portuguese Conference on Controlled Drug Delivery (SPLC-CRS 2013), Valencia, Spain. 2013.

[41] Woertz, C., et al., "Assessment of test methods evaluating mucoadhesive polymers and dosage forms: An overview”, Eur J Pharm Biopharm, 85 (3). 843-53. 2013. 